\title{
PSICOLOGIA NA EDUCAÇÃO: PANORAMA DA PSICOLOGIA ESCOLAR EM ESCOLAS PÚBLICAS DE GOIÂNIA*
}

\author{
Larissa Goulart Rodrigues, \\ da Universidade de Brasília \\ Regina Lúcia Sucupira Pedroza, \\ da Universidade de Brasília
}

\begin{abstract}
Resumo: A psicologia tem construído historicamente estreitas relações com a educação. A psicologia escolar, enquanto campo de atuação da psicologia na educação, é uma das formas que têm se estabelecido em tais relações. Nosso objetivo foi analisar como estão essas relações no contexto goianiense hoje em dia, isso é, qual é o panorama atual da psicologia escolar em escolas públicas da cidade de Goiânia (GO). Para tanto, entramos em contato com as Secretarias Estadual e Municipal de Educação e, a partir da análise de entrevistas, verificamos que é incipiente a inserção do psicólogo escolar nesses âmbitos. Consideramos que alguns passos já foram dados em direção à ampliação desse espaço, embora ainda seja necessário um esforço coletivo para uma efetiva ocupação do mesmo, em prol de processos educativos mais significativos.
\end{abstract}

Palavras-chave: Processos educativos. Psicologia escolar. Escolas públicas. Goiânia.

INTRODUÇÃO

A psicologia tem construído historicamente estreitas relações com a educação. No Brasil essas duas áreas se constituíram mutuamente. A psicologia tem se inserido na educação como um de seus fundamentos científicos e, também, como uma área específica de atuação - a psicologia escolar-, buscando contribuir com processos educativos mais significativos.

\footnotetext{
* Artigo recebido em 10/9/2011 e aprovado em 6/4/2012.
} 
A psicologia escolar é, então, um campo profissional de atuação da psicologia na educação, o qual vem crescendo e conquistando cada vez mais espaço em nossa sociedade. Tem se ampliado e abarcado diversos campos educacionais, como abrigos, penitenciárias, programas de educação comunitária, programas governamentais, universidades e outros, tal como nos apontam Mitjáns Martinez (2009) e Souza (2009).

Entre todos os espaços que o psicólogo escolar pode ocupar atualmente, consideramos ser a escola o campo mais profícuo para sua inserção. Esse é o espaço educacional mais abrangente, pois, comparativamente aos demais, é o que oferece maior demanda para tal profissional, já que atende um número maior de pessoas. Além disso, a parceria do psicólogo com as escolas é bem antiga, tendo sido fundamental para a institucionalização dessa profissão.

Contudo, historicamente, a psicologia tem ganhado presença nas escolas, e na educação de modo geral, por meio de uma postura autoritária, normatizadora, adaptacionista. Sua prática se voltava (e ainda se volta, em muitos casos) ao atendimento de situações-problema na escola, em especial alunos com queixas escolares. Desse modo, a partir de uma atuação clínica, trata-os individualmente, devolvendo-os à sala de aula bem ajustados. Fornece, ainda, prescrições a serem seguidas pelos professores e pela escola, sobretudo no que tange a esses alunos.

Essa prática da psicologia se caracteriza, então, como naturalizadora, ao ponderar que há um modo natural de ser, o qual deve ser seguido por todos. É também descontextualizada, pois desconsidera a história e as relações envolvidas na produção das queixas escolares. Tal perspectiva, conforme retrata Souza (2000), é"fruto da história do pensamento hegemônico de uma Psicologia a serviço da exclusão educacional e social" (p. 106).

Essa visão é que nos leva à situação exposta por Machado e Souza (1997), de que as crianças-problema encaminhadas para atendimento do psicólogo, de um modo geral, são oriundas de escolas públicas e pertencentes aos segmentos mais pobres da população. Seus problemas, isto é, suas dificuldades em aprender, são, então, atribuídas a déficits cognitivos, intelectuais, emocionais ou até sociais. Essa postura reflete, de acordo com Patto (1999), a teoria da carência cultural que se embasa em uma crença na incompetência das pessoas pobres.

Denota-se, assim, o compromisso da psicologia que tem estado ligado aos interesses da classe dominante. Esse papel ao qual a psicologia se preza, em especial no campo educacional, tem sido fruto de reflexões e críticas desde a década de 1980. A partir de então, têm-se buscado novos referenciais para essa prática, visando uma psicologia escolar crítica, refle- 
xiva e comprometida politicamente com uma educação democrática e de qualidade, a partir de uma nova perspectiva.

Esse processo exige do psicólogo uma nova posição política, ou seja, uma aproximação da parcela excluída da população (GUZZO, 2008). Nessa direção, é essencial ao psicólogo escolar assumir o compromisso, proposto por Mitjáns Martinez (2009), com a transformação dos processos educativos e a efetivação de mudanças necessárias à melhoria da educação no país.

O psicólogo escolar - que assume esse compromisso e pretende atuar de acordo com tais princípios - precisa, além de buscar um referencial teórico condizente com essa postura e com a realidade brasileira,

avaliar dimensões psicossociais de comunidades e indivíduos situados historicamente, compreender as redes de apoio, suportes e equipamentos públicos e privados que sustentam as ações comunitárias e a dinâmica dos movimentos sociais presentes em determinados espaços geográficos - quem são e como vivem estudantes, professores, pais e gestores das instituições de ensino e sua comunidade. (GUZZO, 2008, p. 58-59)

Destarte, o psicólogo escolar amplia seu olhar, tirando o foco do indivíduo e passando para as relações sociais e históricas que constituem a escola. Assim, as dificuldades com a escolarização, por exemplo, deixam de ser culpa de alunos pobres e incapazes, sendo associadas a condições e práticas escolares ineficientes e preconceituosas. As relações entre indivíduo e contexto são vistas dialeticamente. E é nessas relações, estabelecidas nos espaços educativos, que o psicólogo escolar intervém.

Souza (2009) enfatiza a importância de que a psicologia escolar atenda aos desafios postos pelas demandas sociais e institucionais. Dessa forma, a partir do novo compromisso político, a psicologia escolar se aproxima mais da função social da escola, contribuindo com o desenvolvimento dos sujeitos dela participantes, com a formação de cidadãos críticos e com a construção de uma sociedade mais democrática e igualitária. Para tanto, é essencial ao psicólogo escolar uma postura ativa e consciente.

Diante desse referencial, consideramos a escola pública como campo propício à atuação do psicólogo escolar socialmente comprometido. Atuando nesse espaço, ele poderá desvelar a anuência de seu comprometimento com as classes populares, contribuindo para melhorar a qualidade da educação que lhes é ofertada.

Contudo, Guzzo (2008) salienta que ainda são poucos os psicólogos que atuam nas redes públicas de educação e, muitos dos que atuam, o fazem de forma precarizada. Para a autora, esse quadro se deve às dificuldades enfrentadas por tais profissionais diante da falta de compreensão do papel 
do psicólogo escolar, em virtude de concepções historicamente constituídas nessa área. Dentre elas, destacam-se a atuação preponderantemente clínica, com atendimento individualizado, voltado às minorias, e seu posicionamento apolítico, pretensiosamente neutro, praticamente inoperante frente aos problemas sociais brasileiros.

Em face dessa incompreensão do papel do psicólogo escolar, deparamo-nos com um panorama de atuação desse profissional bem diversificado pelo país. Há municípios e estados nos quais o psicólogo já foi inserido nas redes de ensino, outros que não contam com tal profissional, entre diversas situações plausíveis.

Uma análise parcial da situação brasileira pode ser encontrada na pesquisa de Souza e Silva (2009), intitulada "A atuação do psicólogo na rede pública de educação frente à demanda escolar: concepções, práticas e inovações". As autoras escolheram alguns estados brasileiros - São Paulo, Minas Gerais, Bahia, Rondônia, Santa Catarina e Paraná - para fomentar discussões no campo da psicologia escolar; no entanto, elas apresentam apenas alguns dados preliminares dos estados de São Paulo e Minas Gerais.

Essa pesquisa teve como objetivo "analisar concepções e práticas desenvolvidas pelos psicólogos da rede pública perante as queixas escolares" (SOUZA e SILVA, 2009, p. 77). Com esse intuito, as pesquisadoras se propuseram a realizar um levantamento bibliográfico da produção acadêmica na área, identificar equipes e psicólogos que atuam nas redes públicas de educação, atendendo a demanda escolar, e também mapear os serviços oferecidos e visitar os profissionais nos municípios.

Posteriormente, a pesquisa foi apresentada no III Congresso Brasileiro de Psicologia: Ciência e Profissão, realizado entre os dias 3 e 7 de setembro de 2010, em São Paulo. Ela foi abordada em dois diferentes simpósios: "A atuação do psicólogo na rede pública de educação na Bahia, em Minas Gerais e Rondônia", coordenado por Silva (2010), e "A atuação do psicólogo na rede pública de educação: concepções e práticas de psicólogos dos estados de São Paulo, Paraná e Santa Catarina", coordenado por Souza (2010).

Essas apresentações evidenciaram a diversidade do panorama brasileiro (que assinalamos anteriormente) em relação à atuação do psicólogo escolar na rede pública de ensino. Contudo, em três dos seis estados abordados, verificamos que a oferta desses serviços é recente. Quanto ao objetivo que orientou essa pesquisa, de avaliar as concepções e práticas desse profissional, constatou-se, na maioria dos casos, o predomínio de uma perspectiva mais tradicional no atendimento à queixa escolar.

Essa pesquisa de Souza e Silva (2009) nos despertou interesse pela aproximação dos nossos objetivos, neste trabalho, em relação ao panorama 
da psicologia escolar na cidade de Goiânia. Embora nossa pesquisa tenha proporções bem menores, identifica-se, porém, com a proposta das autoras, quando essas visam mapear as equipes e psicólogos que atendem as demandas educacionais na rede pública.

Chama-nos a atenção o fato de a região Centro-Oeste não ter sido incluída no estudo. As autoras justificaram afirmando que sua pesquisa dialogará com o trabalho desenvolvido por algumas professoras de psicologia do Distrito Federal. Assim, como o estado de Goiás não foi abordado nesse processo, vemos a potencialidade deste trabalho, de modo a complementar as discussões no campo da psicologia escolar que Souza e Silva (2009) se propuseram a iniciar.

Tal potencial se amplia ao se considerar o número restrito de publicações sobre a psicologia escolar na região. Em relação à situação desse profissional na educação básica da capital goiana, encontramos apenas a pesquisa de Santana (2004). A autora tinha a intenção de "verificar como o psicólogo escolar é inserido no contexto educacional goianiense" (p. 39-40). Dessa forma, na época em que realizou sua pesquisa, a autora encontrou $20 \%$ do total de escolas particulares do município trabalhando com psicólogo, entre as quais somente $2 \%$ apresentavam esse profissional como psicólogo escolar.

Já em relação à rede pública de ensino, tal autora constatou que a atuação de psicólogos na educação municipal se referia apenas à docência ou ao desempenho de outras funções administrativas ou pedagógicas. E na educação estadual existiam 50 profissionais atuando na área da psicologia escolar, estando a maioria sitiada na Superintendência de Ensino Especial e em escolas de educação inclusiva, além de alguns trabalhando em outras funções, como professores do ensino fundamental, médio e técnico, e compondo equipes administrativas e pedagógicas.

Assim sendo, nos propusemos, de certo modo, a atualizar essas informações obtidas por Santana (2004), focando especificamente no ensino público, devido à defesa que propomos de o psicólogo escolar assumir um novo compromisso político junto às classes excluídas em nossa população. Nosso objetivo com este trabalho, portanto, foi conhecer o panorama atual da psicologia escolar no ensino público da cidade de Goiânia (GO).

\section{Método}

\section{Contexto de pesquisa}

O contexto de realização desta pesquisa foi o ensino público de Goiânia (GO), abrangendo tanto a Secretaria Municipal de Educação quanto 
a Subsecretaria Metropolitana de Educação, órgão da Secretaria da Educação do Estado de Goiás responsável pela capital.

O quadro que encontramos então, no ensino público goianiense, se constitui de 323 instituições educacionais municipais, das quais 161 são escolas de educação básica, 105 Centros Municipais de Educação Infantil, 55 estabelecimentos de educação infantil conveniados e dois Centros Municipais de Apoio à Inclusão (CMAls).

Esse quadro se complementa por 134 instituições estaduais de educação, sendo 111 escolas de educação básica, oito escolas conveniadas filantrópicas, quatro escolas conveniadas particulares, seis escolas especiais e cinco centros de capacitação.

Nesse panorama é possível notar uma distinção entre as instituições municipais e as estaduais: apenas o município atende a demanda da educação infantil, por isso a grande quantidade de estabelecimentos voltados a esse público. Já o ensino médio é ofertado principalmente pelo estado, estando incluído no número de escolas de educação básica supracitadas. O ensino fundamental, por fim, é de responsabilidade prioritária do município, cabendo ao estado colaborar nessa oferta. Assim, a quantidade de escolas de educação básica em ambos inclui esse nível de ensino.

Ressaltamos que essa separação advém da organização da educação proposta pela Lei de Diretrizes e Bases da Educação Nacional, em seu título IV, artigos 10 e 11 (BRASIL, 1996).

\section{Participantes}

Foram entrevistadas quatro pessoas em nosso estudo, a saber: uma servidora da Rede de Apoio à Inclusão da Secretaria da Educação do Estado de Goiás; uma servidora do Departamento Pedagógico da Secretaria Municipal de Educação; e duas outras funcionárias dessa Secretaria, sendo cada uma vinculada a um dos dois CMAls existentes no município.

\section{Procedimentos}

Inicialmente, entramos em contato com cada uma das duas Secretarias de Educação, solicitando autorização para a realização da pesquisa. Após o consentimento, buscamos identificar a quais órgãos dessas Secretarias deveríamos recorrer para obter informações acerca de psicólogos atuando na rede pública de ensino.

Na Secretaria da Educação do Estado de Goiás, fomos encaminhadas para conversar com uma profissional da Rede de Apoio à Inclusão, pois os psicólogos atuantes no ensino estadual se encontravam vinculados a essa 
Rede. Como a servidora sugerida não estava disponível naquele momento, agendamos uma entrevista com ela em contato posterior.

Na Secretaria Municipal de Educação, indicaram-nos que procurássemos o Departamento Pedagógico para obter as informações desejadas. Ao chegar ao local, solicitamos alguém que pudesse conversar conosco sobre a presença do psicólogo no ensino municipal. Uma das servidoras se prontificou, sendo entrevistada nessa mesma ocasião.

Por meio dessa última entrevista, sentimos necessidade de realizar um contato com profissionais dos CMAls, para obter maiores informações sobre psicólogos atuando na Secretaria Municipal de Educação. O contato foi feito por telefone, em ambos CMAIs, quando complementamos as informações pretendidas junto às funcionárias que atenderam as ligações.

Todas as entrevistas foram abertas. As duas primeiras, com profissionais das Secretarias de Educação, partiram do questionamento inicial acerca da existência de psicólogos atuando em suas respectivas redes de ensino. A partir dessa resposta, passamos a indagar melhor sobre a caracterização e funcionamento do trabalho desses psicólogos. As outras duas entrevistas se referiram a essas mesmas questões, porém restringindoas aos CMAls.

\section{RESULTADOS}

Por intermédio das entrevistas, constatamos a presença de psicólogos no ensino público estadual. Eles são lotados na Coordenação de Ensino Especial da Secretaria da Educação do Estado de Goiás e se agregam a equipes multiprofissionais, compostas geralmente por fonoaudiólogos e assistentes sociais, além dos psicólogos. Contudo, nem todas as equipes estão completas; em algumas há déficit de um ou mais profissionais, havendo casos em que a "equipe" se configura como um único profissional.

Essas equipes não fazem parte do quadro fixo de profissionais das escolas e atuam como uma espécie de assessores. Os profissionais dessas equipes não costumam ser muito assíduos, comparecendo nas escolas apenas de uma a duas vezes por semana, aproximadamente, posto que cada equipe atende, em média, de dois a quatro estabelecimentos.

A quantidade de escolas que cada equipe atende, bem como a quantidade de horas dedicada a esses atendimentos variam de acordo com a carga horária para a qual foi contratado ou concursado o profissional. Uma parte dessas horas é reservada, ainda, para participação em reuniões semanais de todas as equipes multiprofissionais que compõem a Rede de Apoio à Inclusão na Secretaria da Educação do Estado de Goiás. 
Na cidade de Goiânia, atualmente, há 46 psicólogos em equipes multiprofissionais, com vista à contratação de mais alguns para complementação do quadro dessas equipes. Dentre eles, 24 não possuem vínculo empregatício com a Secretaria da Educação do Estado de Goiás, mas apenas um contrato temporário com a mesma. Esse contrato tem duração média de um ano, podendo ser prorrogado por alguns meses ou até, no máximo, mais um ano.

Os outros 22 psicólogos são profissionais com vínculo efetivo junto a essa Secretaria. No entanto, nunca houve concurso público destinando profissionais para as equipes multiprofissionais. De tal modo, alguns dos psicólogos efetivos foram concursados há 10 anos como técnicos de nível superior, cargo para o qual não havia exigência de habilitação específica, sendo que seu salário atualmente encontra-se altamente desvalorizado, a ponto de nem mesmo atingir o piso salarial de algumas áreas nas quais esses profissionais atuam. Outros psicólogos se efetivaram em concursos para cargos diversos, como professores de educação básica, estando desviados de suas funções.

Já na Secretaria Municipal de Educação, há um número bem mais restrito de psicólogos os quais nem sequer atuam nas escolas, mas encontram-se lotados nos dois CMAls existentes na cidade. Esses centros foram inaugurados em 2006, buscando oferecer atendimento especializado aos educandos com necessidades educativas especiais da rede municipal de educação. Além dos psicólogos, as equipes dos CMAls são compostas de psicopedagogos, fonoaudiólogos e fisioterapeutas.

Em um dos CMAls há seis psicólogos ao todo, três atuando em cada turno - matutino e vespertino. Desses, cinco são concursados e um foi contratado temporariamente. Todos têm formação tanto em psicologia quanto em pedagogia.

No outro CMAl, atuam em média quatro psicólogos por turno, sendo que o número total desses profissionais geralmente oscila entre seis e oito, em virtude dos contratos temporários. Atualmente ele conta com sete psicólogos, dos quais quatro são concursados e possuem formação em psicologia e em licenciatura, e três são contratados. Nesses últimos casos, a maioria se graduou apenas em psicologia e alguns se formaram também no magistério.

Vale ressaltar que, assim como no estado, na rede municipal não houve concurso para psicólogos na área da educação. De tal forma, os profissionais com vínculo efetivo em cada um dos dois CMAls foram concursados como profissionais de educação - geralmente como professores -, tendo sido desviados de função em virtude de sua segunda graduação, a psicologia. 
A atuação dos psicólogos nesses centros, então, tem um caráter mais clínico e está voltada ao atendimento dos alunos com necessidades educacionais especiais da rede municipal de educação, conforme citamos anteriormente. Esses alunos são encaminhados pelas escolas às Unidades Regionais de Educação' que os encaminham aos CMAls.

\section{DISCUSSÃO}

Esse panorama atual que traçamos da psicologia escolar em Goiânia - se comparado à situação exposta por Santana (2004) - nos mostra que em sete anos não houve muitas mudanças.

Na Secretaria da Educação do Estado de Goiás, apesar da instabilidade gerada pelos contratos temporários, o número de psicólogos que atende as escolas permanece praticamente inalterado, com cerca de 50 profissionais. Quando entrevistamos a funcionária dessa secretaria, obtivemos informação da existência de 46 psicólogos, mas, com a perspectiva de contratação de mais alguns, se manterá próximo à quantidade referida por Santana (2004). Aparentemente, esses psicólogos sustentam o mesmo papel, pois permanecem lotados na área do ensino especial, atuando com a inclusão escolar.

Na Secretaria Municipal de Educação, as mudanças no quadro de psicólogos dizem respeito à criação dos CMAls, nesse interstício de sete anos. Dessa forma, o incremento no número desses profissionais remete à criação de um novo espaço de atuação. Contudo, isso não significa necessariamente aumento na quantidade de profissionais com essa formação no município, uma vez que a maioria deles já se encontrava inserida na educação municipal, mas em outras funções.

Ademais das transformações ocorridas nesses sete anos, podemos notar que, em ambos os contextos, o psicólogo se inseriu na educação pelo viés da inclusão. Na Secretaria da Educação do Estado de Goiás, ele atua em equipes multiprofissionais vinculadas à Rede de Apoio à Inclusão e na Secretaria Municipal de Educação, ele se inseriu em Centros Municipais de Apoio à Inclusão.

Consideramos que esse aspecto - somado ao fato de nunca ter havido concurso público para psicólogos na educação - pode estar relacionado a alguns critérios da Lei de Diretrizes e Bases (LDB/1996) da Educação Nacional. No artigo 71, inciso IV, o psicólogo é excluído das despesas educacionais. Nesse sentido, segundo destaca Del Prette (2007), incorre-se muitas vezes em uma impossibilidade de introduzir o psicólogo no quadro funcional da escola. 
Não obstante, essa mesma lei abre uma brecha, em seu artigo $58, \S 1^{\circ}$, ao estabelecer que "haverá, quando necessário, serviços de apoio especializado, na escola regular, para atender às peculiaridades da clientela de educação especial" (BRASIL, 1996). Nesses serviços pode adentrar o psicólogo escolar. Destarte, a educação especial se constitui em um campo fértil de atuação desse profissional e, muitas vezes, torna-se sua principal forma de inserção no contexto educativo. Pode ser que esses campos que se abriram ao psicólogo escolar no ensino público goianiense seja fruto desse processo.

Convém ressaltar que, apesar de o psicólogo se inserir como um "apoio especializado" na área de inclusão na Secretaria Municipal de Educação, ele não se constitui como psicólogo escolar, pois nem mesmo comparece às escolas, ficando sua atuação restrita ao atendimento dos alunos que lhe são encaminhados nos CMAls. Conforme uma das funcionárias entrevistadas afirmou, essa atuação assume um caráter mais clínico.

Notamos, então, influências de uma perspectiva mais tradicional, adaptacionista, na qual o psicólogo diagnostica e trata individualmente cada criança, devolvendo-as devidamente ajustadas às escolas. Se considerarmos que há apenas 13 psicólogos em dois CMAls atendendo todas as 12 regiões administrativas, isso é, as 12 Unidades Regionais de Educação nas quais o município se organiza, a situação fica ainda mais complicada. Torna-se praticamente impossível uma ação comprometida com uma educação de melhor qualidade e mais democrática, tal qual propomos neste trabalho.

Já na Secretaria da Educação do Estado de Goiás, avaliamos que o quadro do psicólogo, em relação à Secretaria Municipal de Educação, encontra-se um pouco mais avançado, pois ele se insere, mesmo que minimamente, nos contextos escolares. Mas por estar também vinculado a uma Coordenação de Ensino Especial, acaba enfocando mais a atuação junto a alunos com necessidades educacionais especiais.

Acreditamos, contudo, que essa atuação acaba se constituindo de forma diversificada, de acordo com a postura, formação e concepções de cada profissional, bem como as relações que eles estabelecem com os demais sujeitos participantes nas escolas que atendem. Cada psicólogo pode agir de determinada maneira - mais individualista ou mais coletivista - em prol da inclusão desses alunos. A falta de contato direto com esses profissionais limita nossa análise, pois sem ela não podemos caracterizar melhor esse quadro, em especial quanto às perspectivas que orientam suas práticas, se são mais tradicionais ou mais críticas.

Entretanto, a partir da entrevista com a servidora responsável pelas equipes multiprofissionais, analisamos que algumas dificuldades podem 
ser encontradas por vários desses profissionais. A primeira delas diz respeito ao vínculo do psicólogo com as escolas. O obstáculo inicial enfrentado nessa direção é a carga horária dedicada ao atendimento das instituições. Como pudemos observar, ela tende a ser reduzida, em virtude do contrato, abrangendo poucas horas, ou mesmo do desdobramento do profissional em atender mais de uma escola.

Outra barreira enfrentada são os contratos temporários. Eles permitem uma quebra no trabalho. Quando o psicólogo começa a entender as relações estabelecidas na escola, seu funcionamento, e começa a efetivar ações em direção à melhoria do processo ensino-aprendizagem naquele espaço, termina seu contrato com a Secretaria de Educação. E quando entra um novo profissional, ele demora um tempo nesse reconhecimento inicial, efetiva algumas ações planejadas e sai. E assim se mantém esse ciclo vicioso.

Contrapondo-se a questões como essas, Guzzo (2008) afirma que: "a produção de conhecimento que pode propiciar a prática de acompanhamento integral à criança e sua família ao lado do professor torna-se inócua em situações em que o profissional da psicologia não esteja presente no cotidiano das instituições" (p. 53).

Desse modo, a atuação do psicólogo nas escolas estaduais goianienses, e também no atendimento realizado nos CMAls, torna-se pouco frutífera, devido à distância em que ele se coloca do espaço escolar. É muito difícil programar intervenções frente às demandas da escola, produzidas em seu interior, sem que se esteja participando do seu cotidiano (GUZZO, 2008). Portanto, é valiosa a inserção do psicólogo escolar no quadro de profissionais de tal instituição, pois, ao participar das relações nela estabelecidas, ele passa a ter um novo olhar sobre elas.

Certamente estamos apontando aqui condições que julgamos ideais para a atuação do psicólogo escolar, em especial sua inserção no quadro funcional das escolas públicas. Sabemos que alcançar esse patamar exige esforço, mas não é impossível. Obviamente não depende apenas do esforço individual de cada psicólogo em mudar suas práticas. Exige também um esforço coletivo, especialmente em prol de políticas públicas que ampliem o espaço para o psicólogo escolar, abrindo vagas em concursos públicos na área, por exemplo.

Meira (2003) ressalta a importância da escola. Para ela, o psicólogo escolar deve assumir um compromisso com essa instituição, pois é dela que emergem as questões para sua prática. Destarte, mesmo que esse profissional esteja fora da escola, a autora defende que ele precisa se colocar dentro da educação. 
Consideramos que não é possível ao psicólogo assumir esse compromisso com a escola sem refletir sobre sua prática e formação, sobre quais concepções as tem orientado. Isso exige uma postura crítica. Requer do psicólogo romper com o modelo de atuação tradicional, questionar e buscar novas respostas, novo sentido em suas ações.

Assim, como aponta Souza (2009), estamos em um momento não mais de fazer a crítica, mas de superá-la, pois “já existem propostas interessantes e críticas de intervenção no campo da educação e estas propostas precisam se tornar mais visíveis entre os psicólogos e socialmente" (p. 181).

Nessa perspectiva, avaliado o panorama da psicologia escolar em Goiânia, consideramos a necessidade de conhecer as intervenções realizadas. Acreditamos na possibilidade de encontrar algum desses profissionais, mesmo sob condições precárias, atuando de maneira criativa e inovadora, em direção a uma prática educacional mais crítica.

Logo, fica-nos evidente, como uma perspectiva que se delineia a partir deste estudo, a relevância de uma pesquisa junto aos psicólogos escolares goianienses, mesmo que poucos, para verificar como está se construindo esse campo de atuação na região. Poderíamos talvez nos aproximar da proposta de Souza e Silva (2009), buscando identificar concepções e práticas desenvolvidas por esses profissionais perante a demanda escolar.

Por intermédio desses momentos, dessas pesquisas, vamos criando oportunidades de dar visibilidade à psicologia escolar nas Secretarias de Educação de Goiânia, evidenciando-Ihes as contribuições que podemos oferecer ao campo da educação. Se não pelo exemplo de experiências inovadoras, pela possibilidade de construí-las.

Além de pesquisas como essas, outras ações podem contribuir para divulgação e ampliação dos âmbitos de atuação da psicologia escolar. Nessa direção, é fundamental estabelecer parcerias com as instituições formadoras desse profissional. É importante investir na formação do psicólogo, tanto básica quanto continuada, especialmente em disciplinas e estágios relacionados à área. É a formação que propicia posturas críticas, a partir do conhecimento dos referenciais que têm orientado a psicologia historicamente, permitindo questioná-los e, em seguida, buscar novas perspectivas de atuação.

As políticas públicas se constituem, ainda, como uma das principais formas de buscar visibilidade para a psicologia escolar. Assim, os psicólogos, principalmente os escolares, precisam assumir seu compromisso político, procurando ampliar seus espaços e condições de atuação, reivindicando concursos públicos na área, instigando projetos de lei nessa direção etc. 
Em Goiânia percebemos algumas movimentações nessa direção, uma vez que recentemente, em setembro de 2010, foi aprovado no município o projeto de lei 292/2005, que torna obrigatória a presença de psicólogos nas escolas da rede municipal de educação. Esse projeto foi proposto por uma vereadora do município e contou com o apoio do Conselho Regional de Psicologia (CRP 09). Essa conquista pode representar um grande avanço para a psicologia escolar em Goiânia. É preciso, agora, continuar lutando para que essa lei seja realmente implementada e que sejam oferecidas condições para sua efetivação.

Enfim, com este trabalho pudemos perceber que a inserção do psicólogo escolar no ensino público em Goiânia ainda é incipiente. Mas alguns passos já foram dados buscando avançar em direção à ampliação desse espaço. O importante é que haja um esforço e participação coletivos para uma efetiva ocupação do mesmo, visando a uma maior aproximação da psicologia com a educação em prol de processos educativos mais significativos.

PSYCHOLOGY IN EDUCATION: THE SCHOOL PSYCHOLOGY SCENARIO IN PUBLIC SCHOOLS

ABSTRACT: Historically, psychology has had a close relationship with education. School psychology, as a field of action for psychology in education, is one of the forms which such relations have established. This study set out to analyze these relations at present in the context of Goiânia, or in other words, examine the current scenario of school psychology in public schools in the city of Goiânia, Goiás. To do so, the State and Municipal Secretariats of Education were contacted and, from an analysis of interviews, it was seen that school psychology is still at an initial stage. Certain measures have already been taken to broaden this space, but collective efforts are still needed to effectively occupy this space, in the interests of more significant educative processes.

KEY WORDS: Educative processes. School psychology. Public schools. Goiânia.

NOTA

1. A Secretaria Municipal de Educação de Goiânia se organiza em 12 Unidades Regionais de Educação, às quais são vinculadas as escolas locais.

\section{REFERÊNCIAS}

BRASIL. Lei de Diretrizes e Bases da Educação Nacional - LDB n. 9.394, 20 de dezembro de 1996. Brasília: MEC, 1996. 
DEL PRETTE, Z. A. P. Psicologia, educação e LDB: novos desafios para velhas questões? In: GUZZO, R. S. L. (Org.). Psicologia escolar: LDB e educação hoje. Campinas: Alínea, 2007. p. 9-26.

GUZZO, R. Psicologia em instituições escolares e educativas: apontamentos para um debate. In: CONSELHO FEDERAL DE PSICOLOGIA, Ano da psicologia na educação: textos geradores. Brasília: CFP, 2008. p. 53-61.

MACHADO, A. M.; SOUZA, M. P. R. As crianças excluídas da escola: um alerta para a psicologia. In: MACHADO, A. M.; SOUZA, M. P. R. (Orgs.). Psicologia escolar: em busca de novos rumos. São Paulo: Casa do Psicólogo, 1997. p. 35-49.

MEIRA, M. E. M. Construindo uma concepção crítica de psicologia escolar: contribuições da pedagogia histórico-crítica e da psicologia sócio-histórica. In: ANTUNES, M. A. M.; MEIRA, M. E. M. (Orgs.). Psicologia escolar: teorias críticas. São Paulo: Casa do Psicólogo, 2003. p. 13-77.

MITJÁNS MARTINEZ, A. Psicologia escolar e educacional: compromissos com a educação brasileira. Psicologia Escolar e Educacional, v. 13, n. 1, p. 169-177, 2009.

PATTO, M. H. S. A produção do fracasso escolar: histórias de submissão e rebeldia. São Paulo: Casa do Psicólogo, 1999.

SANTANA, A. C. Psicólogo escolar para quê? In: CUPOLILLO, M. V.; COSTA, A. O. B. (Orgs.). A psicologia em diálogo com a educação. Goiânia: Alternativa, 2004. p. 35-50.

SILVA, S. M.C. A atuação do psicólogo na rede pública de educação na Bahia, em Minas Gerais e Rondônia. In: Anais do III Congresso Brasileiro Psicologia: Ciência e Profissão. São Paulo, 2010. Disponível em: http://www.cienciaeprofissao.com.br/III/ anais/detalhe. cfm?idTrabalho=10686. Acesso em: 25 jan. 2011.

SOUZA, M. P. R. A queixa escolar na formação dos psicólogos: desafios e perspectivas. In: ROCHA, M.; SOUZA, M. P. R.; TANAMACHI, E. R. (Orgs.). Psicologia escolar: desafios teórico-práticos. São Paulo: Casa do Psicólogo, 2000. p. 105-141.

SOUZA, M. P. R. Psicologia escolar e educacional: em busca de novas perspectivas. Psicologia Escolar e Educacional, v. 13, n. 1, p. 179-182, 2009.

SOUZA, M. P. R. A atuação do psicólogo na rede pública de educação: concepções e práticas de psicólogos dos estados de São Paulo, Paraná e Santa Catarina. In: Anais do III Congresso Brasileiro Psicologia: Ciência e Profissão. São Paulo, 2010. Disponível em: http://www.cienciaeprofissao.com.br/lll/anais/detalhe.cfm?idTrabalho= 10687. Acesso em: 25 jan. 2011.

SOUZA, M. P. R.; SILVA, S. M. C. A atuação do psicólogo na rede pública de educação frente à demanda escolar: concepções, práticas e inovações. In: MARINHO-ARAUJO, C. M. (Org.). Psicologia escolar: novos cenários e contextos de pesquisa, prática e formação. Campinas: Alínea, 2009. p. 75-105. 
LARISSA GOULART RODRIGUES possui graduação em Psicologia pela Pontifícia Universidade Católica de Goiás (2007), especialização em Psicologia Escolar pela mesma instituição (2009) e mestrado em Processos de Desenvolvimento Humano e Saúde pela Universidade de Brasília (2011). Atualmente é psicóloga do Instituto Federal de Educação, Ciência e Tecnologia de Goiás. Tem experiência na área de Psicologia, com ênfase em Psicologia Escolar.

E-mail: larissagr@gmai.com

REGINA LÚCIA SUCUPIRA PEDROZA possui graduação em Psicologia pela Universidade de Brasília (1988), graduação em Licenciatura em Psicologia pela Universidade de Brasília (1989), mestrado em Psicologia pela Universidade de Brasília (1993), doutorado em Psicologia pela Universidade de Brasília (2003) e Pós- Doutorado em Sciences de Education pela Université Paris $V$, René Descartes (outubro 2009 a março de 2010). Atualmente é adjunto da Universidade de Brasília, atuando principalmente nos seguintes temas: educação, formação de professor, formação de educadores para educação em direitos humanos, formação da personalidade, o brincar no desenvolvimento humano, psicanálise e psicologia.

E-mail: rpedroza@unb.br 